\title{
The Fourth International Serum Exchange Workshop to standardize cytoplasmic islet cell antibodies
}

\author{
Report prepared by Å Lernmark ${ }^{1}$, J.L.Molenaar ${ }^{2}$, W. A.M. van Beers ${ }^{2}$, Y. Yamaguchi ${ }^{3}$, S. Nagataki ${ }^{3,}$ J.Ludvigsson $^{4}$ \\ and N. K. Maclaren ${ }^{5}$ on behalf of the Immunology and Diabetes Workshops and participating laboratories*

\begin{abstract}
${ }^{1}$ Department of Medicine, University of Washington, Seattle, Washington, USA ${ }^{2}$ Department of Clinical Immunology, Delft, The Netherlands ${ }^{3}$ The First Department of Internal Medicine, Nagasaki University, Nagasaki, Japan ${ }^{4}$ Department of Pediatrics, University of Linköping, Linköping, Sweden and ${ }^{5}$ Department of Pathology, University of Florida, Gainesville, Florida, USA
\end{abstract}

Quantitative determination of islet cell (cytoplasmic) antibodies (ICA) by indirect immunofluorescence is important to studies of the aetiology and pathogenesis of Type 1 (insulin-dependent) diabetes mellitus. In three previous serum exchange workshops [1-3] the effort was focused on the identification of positive reference sera to be used by all participating laboratories to improve assay sensitivity, precision and reproducibility and yet maintain specificity for disease. One plasma sample from a Swedish female who developed Type 1 diabetes at 12 years of age and was treated with plasmapheresis at the time of clinical onset [4] provided an opportunity to supply numerous laboratories with an ICA sample found positive by all participants. This ICA positive sample has since been used as a reference serum to establish standard curves and express ICA in arbitrary, but common, Juvenile Diabetes Foundation (JDF) units [5]. The success of this investigatorinitiated standardization effort has resulted in the establishment of a proficiency programme under the auspices of the Immunology of Diabetes Workshops (IDW). The ICA proficiency test programme, supported by a grant from the Juvenile Diabetes Foundation International, currently allows nearly 100 laboratories around the world to quality control their own ICA assays by comparison with the results of other participating laboratories and the JDF Standard.

These two standardization efforts, the Serum Exchange Workshops and the Proficiency Program, continue to enhance the validity of the ICA test. Since studies to detect sub-clinical Type 1 diabetes involve assays of samples from non-diabetic individuals both from families with affected members and from the general population, the specificity (negativity in health) of the ICA assay becomes critical. In

* A. Arnaiz-Villena (Madrid, Spain), J. Barbosa (Minneapolis, MN, USA), C. deBeaufort (Luxembourg,), D.Becker (Pittsburgh, PA, USA), F. Becker (Giessen, FRG), C. Betterle (Padova, Italy), E. Bosi (Milan, Italy), G. F. Bottazzo (London, UK), G. Bright, (Jacksonville, FL, USA), P. Colman (Melbourne, Australia), R.L.Dawkins (Perth, Australia), R. B.Elliot (Auckland, New Zealand), Y. Feng (Shanghai, China), F. Gorus (Brussels, Belgium), C. Howard (Beaverton, OR, USA), R. Jackson (Boston, MA, USA), J. Karjalainen (Oulu, Finland), T.Kobayashi (Tokyo, Japan), M. Koelle (Buffalo, NY, USA), H. Kuzuya (Kyoto, Japan), J. Kwan (Toronto, Canada), C.Levy Marchal (Paris, France), U.di Mario (Rome, Italy), R.C.McEvoy (New York, NY, USA), S. Nagataki (Nagasaki, Japan), J.Palmer (Seattle, WA, USA), K.M. Reinauer (Tubingen, FRG), W.J.Riley (Gainesville, FL, USA), W. Scherbaum (UIm, FRG), G. J.P.Singh (Newport Beach, CA, USA), C. Thivolet (Lyon, France), B. Vialettes (Marseille, France) and A.Ziegler (Munich, FRG). the previous ICA Serum Exchange Workshops (1-3), only a few serum samples from healthy individuals were analysed. In the Third ICA Serum Exchange, as many as 36\% (14 of 39) different laboratories found ICA in one or more of 10 random blood bank donor samples, which were distributed often but not exclusively due to poor intra-laboratory precision [3].

The aim of the Fourth ICA Serum Exchange Workshop was therefore to determine inter-laboratory variation of ICA among healthy individuals (control subjects), individuals who later developed Type 1 diabetes (pre-diabetes), as well as from firstdegree relatives of patients with Type 1 diabetes (relatives). In addition, sera from patients with newly diagnosed diabetes (patients) were included as "positive controls". Serum samples were submitted from participants in the USA, in Europe and Japan. The IDW Laboratory in Gainesville, Florida, USA aliquoted and distributed a total of 108 identical samples from 56 control subjects, 21 relatives, eight pre-diabetic patients, and 23 newly diagnosed patients to 46 laboratories worldwide. The JDF Standard was also included. No duplicates were included, and therefore, only inter-laboratory variations were analysed.

ICA titrations were reported from 33 laboratories out of 46 requesting the samples. The majority of the laboratories used the standard indirect immunofluorescence assay $(n=24)$, however, results were also reported following peroxidase staining $(n=4)$, and ELISA $(n=1)$. Frozen sections of human pancreas $(n=24)$ predominated but data from rat $(n=4)$, baboon $(n=1)$ and monkey $(n=1)$ were also reported. One laboratory reported results in a radioimmnoassay which is not presented in this report.

All but two assays (27 of 29;93\%) reported the JDF Standard positive, the reciprocal end-point titre varied between $8-320$. The JDF Standard was used to compute reciprocal end-point titres to JDF units.

In analysing the control samples $(n=56)$ only five $(17 \%)$ laboratories found all the samples negative for ICA. The workshop failed to identify a sample which could be used as a negative reference sample. The closest to negativity was one sample found positive by only $3 \%$ of the participating laboratories. The highest frequency of positivity in these controls was sample 82 found positive by $41 \%$ of the laboratories. The mean level of ICA for the control sera calculated over all the laboratories varied between $0-320 \mathrm{JDF}$ units, whereas the mean level of ICA for each laboratory, calculated over all control samples varied between 0-96 JDF units (Fig, 1). A total number of seven ( $24 \%$ ) laboratories reported ICA positive for more than ten control sera, six (21\%) less than or equal to ten but more than five and $16(55 \%)$ laboratories reported ICA positive for five control samples or less. If this control group was used to define negativity in health (specificity) by these participating laboratories, the results would vary between $27-100 \%$. 


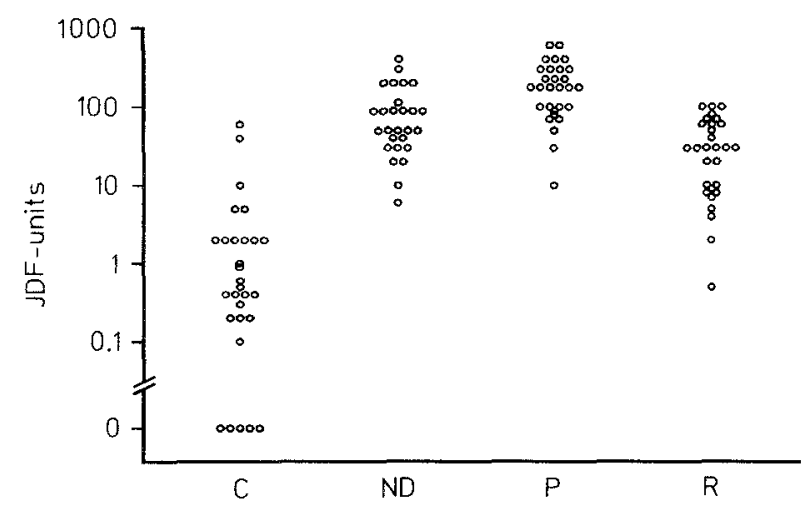

Fig. 1. Mean Juvenile Diabetes foundation (JDF) units for each individual laboratory in serum samples from control subjects (C), newonset patients with Type 1 (insulin-dependent) diabetes (ND), subclinical or pre-diabetic individuals $(\mathrm{P})$ and in first degree relatives (R)

The serum samples from the relatives $(n=21)$ were reported ICA positive by ( $93 \%$ ) of the laboratories. The lowest frequency of $7 \%$ was found for the samples $37,52,54,98$ and 100 , while sample 96 was found positive by $93 \%$ of the participants. The mean ICA level for sample 96 was 217 .

The samples from the pre-diabetes patients $(n=8)$ showed improved inter-laboratory precision compared to the results of the control sera (Fig.1). One sample was found positive by all participants (Sample 10) and two other samples (Samples 61 and 65) were positive in all but one laboratory. The inter-laboratory coefficient of variation, calculated for the samples which scored more than $2 \mathrm{JDF}$ units was $30 \%$.

In the newly diagnosed Type 1 diabetic patients results were similar to those seen in the previous three ICA Serum Exchange Workshops. Two samples were found positive in all assays; in one of these (Sample 68) the average level of ICA was 360 (range 20-640), and in the other (Sample 85) 106 (range 10-640) JDF Units.

In conclusion, the Fourth Workshop on ICA standardization using the JDF standard to express levels of ICA shows that the assay sensitivity has improved compared to previous workshops. Thus, 11 of 24 laboratories reported a sensitivity of more than $60 \%$. The mean sensitivity in the 24 laboratories was $59 \pm 14 \%$. A specificity of more than $90 \%$ was obtained in 17 of 24 laboratories. The mean specificity was $90 \pm 12 \%$. The overall specificity in this workshop was therefore also improved. In addition, too many laboratories appeared to be unable to find ICA at low levels and thus showed low sensitivity.

The ICA assay is therefore faced with two main problems. One is the variable lower detection limit. Furthermore, some laboratories are unable to measure certain high titre sera and this is unlikely to be a detection limit problem. The other problem is the low specificity i. e. a high frequency of false positive results. Assuming that all of the samples from the control subjects do in fact lack ICA, $87 \%$ of the laboratories report false positive results.

These data unfortunately do not permit the present control sera to define the normal range of ICA in JDF units. It is suspected, based on previous analyses, that part of the present assay inconsistencies between laboratories may be due to a marked variation in the quality and character of the pancreas used for the frozen sections $(6,7)$.

In the Fifth ICA Serum Exchange Workshop it is intended to evaluate and to assign ICA standard sera covering the range 5-80 JDF units, and to secure large volumes of such graded standards for use in future exchanges. This workshop will also address the question of variability between human pancreata used for the frozen sec- tions. Finally, ICA associated with Type 1 diabetes in different racial groups will be compared.

Acknowledgements. Support for the Fourth ICA Serum Exchange was obtained from the Nichols Institute, Henning Berlin GMBH, Novo-Nordisk A/S, Speciality Laboratories, Inc., Dickinson \& Co., and Sandoz Research Institute. Secretarial assistance by Ms. S. Blaylock is greatly acknowledged.

\section{References}

1. Bottazzo GF, Gleichmann H (1986) Workshop report. Immunology and diabetes workshops: report of the first international workshop on the standardization of cytoplasmic islet cell antibodies. Diabetologia 29:125-126

2. Bonifacio E, Dawkins RL, Lernmark $\AA$ (1987) Immunology and diabetes workshops: Report of the second international workshop on the standardization of cytoplasmic islet cell antibodies. Diabetologia $30: 273$

3. Boitard C, Bonifacio E, Bottazzo GF, Gleichmann H, Molenaar J (1988) Immunology and diabetes workshop: Report on the third international (Stage 3) workshop on the standardization of cytoplasmic islet cell antibodies. Diabetologia 31: 451-452

4. Ludvigsson J, Heding L, Liedén G, Marner B, Lernmark A (1983) Plasmapheresis in the initial treatment of insulin-dependent diabetes mellitus in children. Br Med J 286: 176-178

5. Bonifacio E, Lernmark $\AA$, Dawkins RL et al. (1988) Serum exchange and use of dilutions have improved precision of measurement of islet cell antibodies. J Immunol Methods 106: 83--88

6. Gleichmann H, Bottazzo GF (1987) Progress towards standardization of cytoplasmic islet-cell antibody assay. Diabetes 36: $578-584$

7. Landin-Olsson M (1990) Precision of the islet cell antibody assay depends on the pancreas. J Clin Lab Anal 4: 289-294

Prof. Å. Lernmark

University of Washington

R. H. Williams Laboratory

Department of Medicine, RG-20

Seattle, WA 98195

USA

For more information regarding the Proficiency Program under the auspices of the Immunology of Diabetes Workshops please contact: Dr. N.K. Maclaren

Department of Pathology

University of Florida

1600 S. W. Archer Road

Box J-2, JHMHC

Gainesville, FL 32610

USA

For more information on islet cell antibodies associated with Type 1 (insulin-dependent diabetes in different racial groups please contact:

Dr. R. L. Dawkins

$5^{\text {th }}$ ICA Exchange

Department of Clinical Immunology

Royal Perth Hospital

Box X 2213, GPO

Perth

Western Australia 6001

Australia 